
Revue Revue de l'histoire des religions
de Ihistoire des religions
$1 \mid 2019$
Corps, ascèse et extinction dans l'histoire du bouddhisme (Inde, Corée, Japon)

\title{
Corps, ascèse et extinction dans l'histoire du bouddhisme (Inde, Corée, Japon)
}

Avant-propos

\section{Guillaume Ducœur}

\section{OpenEdition \\ Journals}

Édition électronique

URL : https://journals.openedition.org/rhr/9371

DOI : $10.4000 /$ rhr.9371

ISSN : 2105-2573

Éditeur

Armand Colin

\section{Édition imprimée}

Date de publication : 1 mars 2019

Pagination : 5-9

ISBN : 978-2-200-93230-5

ISSN : 0035-1423

Référence électronique

Guillaume Ducœur, "Corps, ascèse et extinction dans l'histoire du bouddhisme (Inde, Corée, Japon) », Revue de l'histoire des religions [En ligne], 1 | 2019, mis en ligne le 01 janvier 2021, consulté le 07 janvier 2022. URL : http://journals.openedition.org/rhr/9371 ; DOI : https://doi.org/10.4000/rhr.9371 


\section{Corps, ascèse et extinction dans l'histoire du bouddhisme (Inde, Corée, Japon)}

Avant-propos

L'énonciation récurrente et ordonnancée à l'identique des quatre nobles vérités (caturāryasatya ${ }^{1}$ ), dans l'ensemble des Sūtra et des Vinaya des écoles bouddhiques anciennes, tant sthavira que mahāsāṃghika, atteste que cet enseignement de structure quaternaire, basée sur le diagnostic de la médecine indienne, et au fondement de la doctrine (dharma) du Buddha historique repose sur une analyse du fonctionnement physiologique et psychologique des êtres vivants. Les éléments constitutifs du corps humain, notamment les organes des sens (indriya), sont autant d'ouvertures sur le monde sensoriel considéré par les ascètes (śramaṇa) bouddhistes comme source de désirs (tṛ̣ṇā) qui contraignent l'individu (pudgala) à vouloir y revenir sans cesse pour en jouir de nouveau.

Mais à la détermination du désir comme source de toute souffrance (duhkha), tant physique que morale ou psychologique, s'impose également, dans la théorie de la production conditionnée (pratītyasamutpāda) énoncée dans les sources bouddhiques de ces mêmes écoles anciennes, l'ignorance (avidyā) comme origine des re-naissances (punarjanman) ou des re-morts (punarmṛtyu) dans le monde phénoménal, des ré-existences (punarbhava) infinies dès lors génératrices d'innombrables souffrances.

1. Constatation de la douleur, origine de la douleur, suppression de la douleur, chemin menant à la suppression de la douleur. 
Aussi, comment entendre ces deux doctrines qui mettent en avant soit le désir soit l'ignorance comme facteur originel de la douleur inhérente à toute vie humaine et qui, assez tôt, furent plus ou moins conciliées par les spécialistes du dharma bouddhique? Le non-retour au monde des désirs ou au monde phénoménal résulterait alors soit de l'extinction (nirvāṇa) du désir d'existence (bhavatṛ̣ṇā) par une ascèse corporelle rigoriste (dhuta) qui trouverait plus tard sa régularisation dans la communauté (saṃgha) grandissante par l'observance du chemin à huit auxiliaires (aștạngamārga), soit de la cessation (nirodha) de l'ignorance par le développement de la connaissance discernante (prajñā) qui conduirait à l'aperception du mécanisme des changements d'états ou transmigrations (saṃsāra) relevant de la production conditionnée sans fin (anitya) de toute chose (dharma).

Le présent dossier Corps, ascèse et extinction dans l'histoire $d u$ bouddhisme propose de revenir sur cette dichotomie doctrinale à travers quatre contributions qui portent sur des pratiques ascétiques bouddhiques relevant de sphères culturelles d'implantation différente, à savoir l'Inde, la Corée et le Japon. La problématique d'ensemble est introduite par Guillaume Ducœur qui, dans sa présentation de l'histoire rédactionnelle de l'épisode des six années de pratique des austérités de Sākyamuni conservé dans différentes sources textuelles des écoles anciennes et sur des figurations artistiques, montre les possibles divergences survenues au sein du saṃgha même entre des bhikșu qui prétendaient toucher de leur corps, vivifié par un ascétisme rigoriste, le nirvāna et ceux qui revendiquaient toucher de leur connaissance discernante la profonde réalité de toute chose. Se pose ici la difficulté de restituer l'histoire des pratiques bouddhiques anciennes dès lors que les sources textuelles qui sont parvenues jusqu'à nos jours relèvent avant tout d'écoles anciennes qui ont fini par donner la primauté à la connaissance spéculative et discernante et par rejeter toute pratique ascétique rigoriste remontant probablement aux premières décennies du saṃgha et dont les épisodes et de Śākyamuni émacié et du schismatique Devadatta ne sont plus que des témoignages indirects.

Dans le domaine de l'ascétisme bouddhique porté à son extrême se trouve être la tradition de l'ignition du corps telle qu'elle est déjà rapportée par Nicolas de Damas (Strabon, Géographie 15.1.73) au 


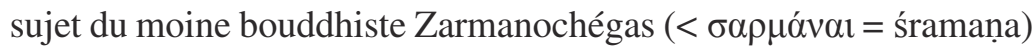
qui accompagna une ambassade indienne venue de Barygaza auprès de l'empereur Auguste en 20 av. J.-C. et qui s'autoimmola à Athènes. Cette tradition bouddhique qui repose sur une pratique ancienne dont l'origine est certainement à rechercher dans la mouvance śramanique pré-bouddhique des éveilléspour-soi (pratyekabuddha) prit notamment son essor en Chine dès le $\mathrm{V}^{\mathrm{e}}$ siècle apr. J.-C. suite à l'importance qui fut conférée au Sūtra du lotus de la vraie doctrine (Saddharmapuṇdarīkasūtra) dans lequel il est rapporté (chapitre XXII) que le bodhisattva Sarvasattvapriyadarśana avait considéré la manifestation des pouvoirs surnaturels (ṛddhi) inférieure à l'abandon de sa propre personne (ātmabhāvaparityāga) en l'honneur du Buddha. Après avoir absorbé, durant douze années, des parfums (gandha) et des huiles (taila), il s'était arrosé d'huile de campaka (Magnolia Champaca), s'était donné à lui-même la bénédiction et avait consumé son propre corps par le feu (svaṃ kāyam prajvālayāmāsa) pour rendre hommage (pūjā) au Tathāgata et à son Sūtra. En 1960, le sinologue Jacques Gernet (1921-2018) avait publié une étude sur la pratique d'ignition des moines bouddhistes chinois entre le $\mathrm{V}^{\mathrm{e}}$ siècle et le $\mathrm{x}^{\mathrm{e}}$ siècle. À cette dernière, Arnaud Brotons vient apporter un complément important en retraçant cette même tradition mahāyānique de l'immolation de soi dans l'histoire du Japon du $\mathrm{VI}^{\mathrm{e}}$ siècle au XIII ${ }^{\mathrm{e}}$ siècle. L'étude des sources nippones confirme que cette pratique de se brûler une partie du corps ou bien de s'auto-immoler participe de la monstration des capacités ascétiques acquises par les moines bouddhistes spécialistes du Sūtra du lotus et de l'édification des dévots qui, en prenant part à l'organisation de ces exploits, tissaient un lien karmique avec les moines, pouvaient entr'apercevoir les Paradis des bodhisattva auxquels ces derniers s'élevaient et espérer ainsi obtenir en retour le bénéfice de leur bienveillance à leur égard.

De son côté, Kyong-Kon Kim s'est attaché à saisir toute l'ambivalence que peut encore susciter la tradition ascétique rigoriste indienne, qui se sinisa avant de pénétrer en Corée au VII ${ }^{\text {e }}$ siècle ap. J.-C. au plus tard, dans des écoles bouddhiques coréennes contemporaines comme Jogye-jong. Après la présentation d'une quinzaine de sources textuelles indo-chinoises dans lesquelles sont énumérés les dhuta, l'auteur en a retrouvé les 
résonances dans des traités coréens, aujourd'hui difficiles d'accès, et démontre ainsi que ces pratiques ascétiques s'enracinant dans l'histoire des écoles bouddhiques anciennes furent perpétuées par les moines mahāyānistes tout au long des siècles dans la péninsule coréenne. Ce qui retiendra assurément l'attention de l'historien des religions est la ou les justifications doctrinales, empiriques mais aussi institutionnelles qui furent autant de facteurs de conservation de cet ascétisme au sein même des communautés monastiques coréennes, notamment sŏn, en parallèle des écoles scolastiques, ainsi que la figure de Śākyamuni ayant pratiqué les austérités durant six années qui redevint un modèle de pratique et de vertu et par ce biais d'obtention du parfait et complet éveil (samyaksambodhi).

Enfin, il n'était guère possible d'aborder un tel sujet sur la place du corps et de l'ascétisme dans l'histoire du bouddhisme sans faire référence au particularisme du shugendō dont l'histoire même au Japon atteste encore une fois combien les tendances ascétiques rigoristes n'ont laissé que très peu de traces écrites. Dans sa contribution à ce dossier, Alexandre Goy présente la traduction de passages importants du Shugen shuyō hiketsu-shū ou Recueil des arcanes essentiels à la pratique du shugen rédigé par le moine Akyūbō Sokuden qui vécut au XVI ${ }^{\mathrm{e}}$ siècle. Ce traité est l'un des plus anciens aujourd'hui conservés qui permet de comprendre le travail d'harmonisation que ce moine opéra entre la tradition ascétique bouddhique japonaise transmise de maître à disciples et tenue secrète durant des siècles et la doctrine mahāyānique. Les mises en corrélations entre les parties du corps, les vêtements portés par le shugenja ou yamabushi, les nombres traditionnels de vertus et d'observances ou encore la forme de certains akșara sanskrits sont autant d'identifications symboliques qui œuvrèrent à définir cette voie ascétique japonaise comme un chemin mahāyānique ardu menant au surgissement de la bouddhéité inhérente à chaque être.

Ce dossier ambitionne donc de donner matière à réflexion sur l'une des composantes fondamentales de la vie de renoncement des religieux-mendiants (bhikșu) bouddhistes dont les origines remontent aux pratiques ascétiques des courants śramaniques de l'Inde ancienne. L'histoire du bouddhisme, sur le long terme, donne à entrevoir les modifications qui s'imposèrent progressivement aux membres du samgha en ce domaine par suite de 
l'adoption de modes de vie plus sédentarisés, du développement d'approches plus spéculatives et cognitives de la doctrine du fondateur, de l'émergence du concept mahāyānique de bouddhéité universelle supplantant l'état d'ascète accompli ou arhattva, etc. Elle montre également que malgré ces changements, malgré les milieux culturels dans lesquels se diffusa le bouddhisme, cette tradition ascétique rigoriste indienne a toujours su se maintenir au cours des siècles, a su se réinventer, se diversifier voire être revendiquée comme modèle à suivre dans des crises identitaires ou disciplinaires. Le corps apparaissait dès lors comme l'expression la plus vivante et la plus manifeste des quatre nobles vérités et comme le véhicule toujours le plus à même pour parvenir au but final, celui de la délivrance du monde des désirs et de ses souffrances.

gducoeur@unistra.fr 